\title{
Japanese industry rallies around superconductors
}

\section{- New research centre planned \\ - International cooperation hopeful}

\section{Tokyo}

JAPAN's Ministry of International Trade and Industry (MITI) looks set to succeed in persuading the giants of Japanese industry to join forces in researching the recently discovered high-temperature superconductors. A massive new research centre, funded by industry, will be established and will help to provide a total national investment in superconductor research that will at least equal that of the United States.

First news of the centre was leaked in the summer from closed sessions of MITI's high-temperature superconductor research committee, a key advisory group whose members are drawn from industry and academic institutions (see Nature 328, 282 ; 1987). According to Professor Shoji Tanaka of Tokyo University, one of the committee members, the centre will be divided into an information centre and a research laboratory.

Eighty to ninety companies are interested in joining the information centre, says Tanaka, and each will contribute an annual subscription of $\$ 10,000$ to give the centre a million-dollar-a-year budget. Along with the electric utility, electronic and cable manufacturing companies, securities companies, banks and construction companies are among potential members. The latter are looking for investment opportunities and for the big construction works that would be necessary for magnetically levitated trains.

But the really big money will go to the centre's research laboratory. Some 35-38 companies, including such electronics giants as Toshiba and Hitachi, will participate, according to Tanaka. Each will contribute about $¥ 100$ million $(\$ 700,000)$ at the start and $¥ 20$ million $(\$ 140,000$ ) a year for running costs.

Setting that money alongside the approximately $¥ 6,000$ million ( $\$ 42$ million) in superconductor research spending that the two big technology agencies, MITI and the Science and Technology Agency, are asking for in their 1988 budgets puts Japan at least level with the United States in its total commitment to superconductor research. US government and industry will together spend $\$ 117$ million in 1988 , according to Charles Laverick, a consultant for Westinghouse Research and Development Center and one of the authors of the US National Academy of Sciences report on superconductor research. And many believe that estimate may be optimistic.

The new centre will apply to MITI for classification as a non-profit organization, so avoiding corporate and property taxes, according to Rizaburo Nezu of MITI's Agency of Industrial Science and Technology. He says the information centre is expected to be in place in Tokyo within the next two or three months, a little later than had been thought, while the laboratory should be built by next summer.

How will the new centre be viewed by Japan's foreign competitors? It will no doubt stir painful memories of the very-large-scale integrated circuit research project which, in 1976, brought together competing electronics companies and government laboratories under MITI's sponsorship. Within a year of the project's completion in 1980 , Japanese companies had seized 70 per cent of the world market for memory chips, previously dominated by US companies. But this time there is a big difference, says Tanaka. The laboratory will be concerned primarily with basic research and, if Tanaka and Nezu have their way, it will be open to participation from foreign companies and researchers. However, Nezu admits that no attempt to approach foreign companies has yet been made.

Tanaka, best known for his group's confirmation of Bednorz and Müller's discovery of high-temperature superconductivity, is also one of Japan's leading semiconductor researchers. And he is most concerned that superconductor research should not follow semiconductor research as a source of a bitter trade dispute with the United States. But, although Tanaka strongly favours international cooperation, he says Japan must be "very careful" about the military aspects of some US research.

Much will depend on attitudes in the United States too. The US administration sees it as vital that the United States should win the superconductor race in order to restore confidence in the nation's ability to innovate. And there is an entrenched belief that joining forces with Japan would only make it easier to export US basic research. Others, however, estimate that practical applications of the new superconductors are decades away except in a few specialized areas - and see a golden opportunity for long-term international collaboration in truly basic research.

\section{Antarctic not the place for sun worshippers}

\section{Washington}

ANTARCTIC explorers are going to have to pack plenty of sun-tan oil along with their dog-sleds if the latest calculations of the effects of the depletion of the ozone layer prove correct

According to Peter Wilkniss, director of polar programmes at the US National Science Foundation, a day under the Antarctic ozone hole will provide a dose of ultraviolet radiation four times as great as a day on the beach at Miami.

Wilkniss, who gave evidence to a Senate Environment and Public Works Committtee last week, says he finds himself in the difficult position of being "responsible for the first US population living under a depleted ozone shield" and just does not know what measures are going to prove necessary. All he has to go on are some preliminary calculations that assume a worst case in which stratospheric ozone levels fall to 100 dobson units, the expedition crew are outside for the polar day and the Sun is high in the sky.

The worst-case conditions may not be overly pessimistic: satellite observations show ozone levels of $\mathbf{1 0 5}$ dobson units over the US McMurdo station (although they have yet to be squared with simultaneous ground records of 127 dobson units), and the Sun does rise well above the horizon at the more northerly stations, although not at the South Pole.

Wilkniss wants to obtain data on Antarctic ultraviolet levels as quickly as possible. Measurements will soon be available from equipment which was installed at the South Pole last year, but they are not likely to provide a complete answer: it is still dark at the South Pole when the ozone hole is at its deepest. Next year, monitoring programmes will be under way at all US stations and a safety panel will assess what precautions are necessary.

Part of the problem in estimating the dangers, Wilkniss says, is that crew who over-winter in the Antarctic spend 6-8 months without sunlight. That is known to affect their hormonal and immune systems and may render them more susceptible to harm from high ultraviolet light levels when the polar spring arrives and the ozone hole deepens.

The biggest immediate danger is to the eyes. Temporary 'snow blindness' is already quite common and extra protection against increased ultraviolet light may be necessary. Further in the future are heightened risks of skin cancer.

Alun Anderson 